\title{
Determination of the content of total polyphenols, non-tannin polyphenols and tannins in five species of the genus Teucrium $\mathrm{L}$.
}

\author{
ŽELJAN MALEŠ ${ }^{1}$ \\ KROATA HAZLER PILEPIĆ ${ }^{1}$ \\ MIRZA BOJIĆ2 \\ ZORAN TATALOVIĆ1 \\ ${ }^{1}$ University of Zagreb \\ Faculty of Pharmacy and Biochemistry \\ Department of Pharmaceutical Botany \\ Schrottova 39 \\ 10000 Zagreb \\ Croatia \\ ${ }^{2}$ University of Zagreb \\ Faculty of Pharmacy and Biochemistry \\ Department of Medicinal Chemistry \\ Ante Kovačića 1 \\ 10000 Zagreb \\ Croatia

\section{Correspondence:} \\ Željan Maleš \\ University of Zagreb \\ Faculty of Pharmacy and Biochemistry \\ Department of Pharmaceutical Botany \\ Schrottova 39 \\ 10000 Zagreb \\ Croatia \\ E-mail: zmales@pharma.hr
}

Key words: Teucrium L., total polyphenols, non-tannin polyphenols, tannins, spectrophotometry, quantitative analysis

Received November 24, 2014

Revised November 19, 2015.

Accepted November 19, 2015

\section{Abstract}

Background and Purpose: Many species of the genus Teucrium L. are used in folk medicine. These species contain various chemical compounds that contribute to its biological activities. No literature could be found in respect of the determination of total polyphenols, non-tannin polyphenols and tannins in the species T. halacsyanum Heldr., T. hyrcanicum L. and T. scorodonia L. Quantitative analysis of polyphenols and tannins was therefore performed.

Materials and Methods: Plant material was collected over two consecutive seasons in the Pharmaceutical Botanical Garden "Fran Kušan" of the Faculty of Pharmacy and Biochemistry, University of Zagreb, Croatia. The content of total polyphenols, non-tannin polyphenols and tannins was determined by combination of spectrophotometric and hide powder method.

Results: The quantity of total polyphenols of investigated species ranged from 0.87 to $4.1 \%$. The content of polyphenols unadsorbed on hide powder (non-tannin polyphenols) was between 0.83 and $3.4 \%$, while the quantity of tannins ranged from 0.04 to $1.4 \%$. The sample of $\mathrm{T}$. scorodonia that grows along the hedge contained the highest content of total polyphenols (4.1\%) and tannins (1.4\%), while the highest quantity of non-tannin polyphenols was found in the sample of T. chamaedrys (3.4\%) collected in 2013. The sample of $\mathrm{T}$. botrys collected in 2012 contained the lowest amounts of all investigated compounds.

Conclusion: For the first time the content of total polyphenols, nontannin polyphenols and tannins in the species T. halacsyanum, T. hyrcanicum and $\mathrm{T}$. scorodonia is reported. The content of all investigated compounds depended on the plant species investigated and year of collection.

\section{INTRODUCTION}

Teucrium L. is a large genus of about 200 species of flowering plants 1 in the family Lamiaceae (1). The species T. botrys L., T. chamaedrys L. and T. scorodonia L. are widespreaded in Croatia (2). T. halacsyanum Heldr. grows in the Eastern Mediterranean (Greece and Egypt) (3), while T. hyrcanicum $\mathrm{L}$. is distributed in the region of Caucasus, Iran and Turkey (4).

The species of the genus Teucrium contain various secondary metabolites such as flavonoids, phenolic acids, tannins, bitter principles, essential oil, saponins, sterols, sugars and microelements that contribute 
to its biological activities (4-8). Many species of the genus are used in folk medicine as antidiabetics, diuretics, diaphoretics, expectorants, spasmolytics, antioxidants, antiseptics and stomachics $(7,9)$.

Polyphenols are known as antioxidants, while tannins comprise a large group of complex substances that are widely distributed in the plant kingdom and have antidiarrhoeal, antioxidant and antiseptic properties (10).

As no literature data could be found in respect of the determination of total polyphenols, non-tannin polyphenols and tannins in the species $T$. halacsyanum, T. hyrcanicum and T. scorodonia, quantitative analysis of total polyphenols, non-tannin polyphenols and tannins in five cultivated species of the genus Teucrium was conducted.

\section{MATERIALS AND METHODS}

\section{Plant material and chemicals}

Five species of the genus Teucrium (T. botrys, $T$. chamaedrys, T. halacsyanum, T. hyrcanicum and T. scorodonia) were cultivated in the Pharmaceutical Botanical Garden "Fran Kušan" of the Faculty of Pharmacy and Biochemistry University of Zagreb. The garden is located in the northern part of Zagreb - 45 $50^{\prime} \mathrm{N}, 15^{\circ} 59^{\prime} \mathrm{E}$, at the $195 \mathrm{~m}$ height above sea-level, with prevailing pseudo clay and western exposition. Climate is temperate with moderate changes in temperature and rainfall distributed throughout the year without extreme dry periods. The greatest amount of precipitation falls in late spring and autumn, and between them is a moderate dry period. The average monthly temperature in the coldest month (January) is not less than $-0.4^{\circ} \mathrm{C}$, while the warmest month (July) does not exceed $22.2^{\circ} \mathrm{C}$.

Voucher specimens (No. 125000-125011) were deposited in the Herbarium of the Department of Pharmaceu- tical Botany of the Faculty of Pharmacy and Biochemistry, University of Zagreb. The aerial parts were collected during flowering period in July 2012 and 2013 and dried at room temperature.

All solvents (Kemika, Zagreb) and reagents (Merck, Germany) used were of analytical grade.

\section{Quantitative analysis}

The measurements were carried out using spectrophotometer Varian Cary 50 Bio (Varian Inc., USA).

The determination of total polyphenols, polyphenols unadsorbed on hide powder (non-tannin polyphenols) and tannins was performed by the spectrophotometric method with phosphorous - tungsten acid and hide pow$\operatorname{der}(11,12)$.

\section{Statistical analysis}

The content of total polyphenols, non-tannin polyphenols and tannins was evaluated upon five independent analyses and data were expressed as means \pm SD. The statistical analysis between samples collected in 2012 and 2013 was performed by Student's $t$-test $(\alpha=0.05)$ using R program (www.r-project.org).

\section{RESULTS AND DISCUSSION}

The results of quantitative analysis of total polyphenols, non-tannin polyphenols and tannins are presented in Table 1.

The quantity of total polyphenols of investigated samples ranged from 0.87 to $4.1 \%$. The content of total polyphenols in the sample of the species $T$. scorodonia that grows along the hedge was found to be approximately

TABLE 1. Dried basis content of total polyphenols $(w, \%)$ in the investigated species of the genus Teucrium.

\begin{tabular}{|c|c|c|c|c|c|}
\hline Sample & Species & Year of collection & Total polyphenols (\%) & Non-tannin polyphenols (\%) & Tannins (\%) \\
\hline 1 & T. botrys & 2012 & $0.87 \pm 0.04$ & $0.83 \pm 0.01$ & $0.04 \pm 0.03$ \\
\hline 2 & T. botrys & 2013 & $1.68 \pm 0.04^{* *}$ & $1.15 \pm 0.01^{* *}$ & $0.53 \pm 0.03^{* *}$ \\
\hline 3 & T. chamaedrys & 2012 & $3.13 \pm 0.01$ & $3.02 \pm 0.06$ & $0.11 \pm 0.03$ \\
\hline 4 & T. chamaedrys & 2013 & $3.5 \pm 0.2$ & $3.4 \pm 0.2$ & $0.17 \pm 0.04^{*}$ \\
\hline 5 & T. halacsyanum & 2012 & $2.2 \pm 0.1$ & $1.14 \pm 0.01$ & $1.06 \pm 0.09$ \\
\hline 6 & T. halacsyanum & 2013 & $4.0 \pm 0.1^{* *}$ & $3.0 \pm 0.2^{*}$ & $0.99 \pm 0.03$ \\
\hline 7 & T. hyrcanicum & 2012 & $2.8 \pm 0.1$ & $2.2 \pm 0.09$ & $0.61 \pm 0.03$ \\
\hline 8 & T. hyrcanicum & 2013 & $2.11 \pm 0.03$ & $1.60 \pm 0.03$ & $0.51 \pm 0.01$ \\
\hline 9 ho & T. scorodonia & 2012 & $2.4 \pm 0.01$ & $2.24 \pm 0.07$ & $0.19 \pm 0.04$ \\
\hline 10 ho & T. scorodonia & 2013 & $1.83 \pm 0.08^{*}$ & $1.5 \pm 0.2$ & $0.4 \pm 0.1$ \\
\hline 11 he & T. scorodonia & 2013 & $4.1 \pm 0.1$ & $2.7 \pm 0.1$ & $1.4 \pm 0.2$ \\
\hline
\end{tabular}

$\%=$ Mean $\pm \mathrm{SD}, \mathrm{n}=5$, ho $=$ hotbed, he $=$ hedge, ${ }^{*} \mathrm{p}<0.05,{ }^{* *} \mathrm{p}<0.01$. 
twice higher, than the content in the sample of T. scorodonia from the hotbed.

The content of polyphenols unadsorbed on hide powder (non-tannin polyphenols) was between 0.83 and $3.4 \%$. The quantity of non-tannin polyphenols in the sample of the species $T$. scorodonia that grows along the hedge was found to be higher in comparison with the content in the sample of $T$. scorodonia from the hotbed.

The investigated samples contained 0.04 to $1.4 \%$ tannins. The content of tannins in the sample of the species T. scorodonia that grows along the hedge was found to be approximately five times higher than the content in the sample of T. scorodonia from the hotbed (Table 1.).

The content of non-tannin polyphenols in comparison with content of tannins was greater in all investigated Teucrium species.

The above results indicate high variability in the content of total polyphenols, non-tannin polyphenols and tannins that depended on the plant species investigated and the slight weather conditions differences between two compared sampling years (13). Meteorological conditions for July 2012 and 2013 in Zagreb were described as extremely warm, but an average rainfall in July 2012 was slightly higher.

The investigated samples contained lower quantities of total polyphenols, non-tannin polyphenols and tannins in comparison with some other native Teucrium species (6). The chemical variability in Teucrium species may reflect environmental influence on the content of investigated compounds (14). The content of total polyphenols and tannins in the samples of the species T. botrys and $T$. chamaedrys is significantly lower in comparison to those reported Jurišić Grubešić et al. (5). However, this can be attributed to the different method used for quantitative analysis of polyphenols and tannins.

To the authors' knowledge, based on literature search this is the first time that the content of total polyphenols, non-tannin polyphenols and tannins in the species $T$. halacsyanum, T. hyrcanicum and T. scorodonia is reported. Polyphenols represent most abundant and widely distributed antioxidants that have beneficial health promoting effects. Our results confirm that Teucrium species are good source of polyphenols and can be basis for further biological studies.

\section{REFERENCES}

1. TUTIN T G, HEYWOOD V H, BURGES N A, MOORE D M, VALENTINE D H, WALTERS S M, WEBB D A 1972 Flora Europaea. Vol. 3. Cambridge University Press, Cambridge, p 129

2. NIKOLIĆ T ed. Flora Croatica Database 2015. University of Zagreb, Faculty of Science (http://hirc.botanic.hr/fcd).

3. POLINUM O 1980 Flowers of Greece and the Balkans a field guide. Oxford University Press Inc., Oxford, p 388

4. KAZEMIZADEH Z, BASIRI A, HABIBI Z 2008 Chemical composition of the essential oil of Teucrium hyrcanicum and T. chamaedrys L. subsp. chamaedrys from Iran. Chem Nat Comp 44: 651-653 http://dx.doi.org/10.1007/s10600-008-9164-2

5. JURIŠIĆ GRUBEŠIĆ R, KREMER D, VLADIMIR-KNEŽEVIĆ S, VUKOVIĆ RODRIGUEZ J 2012 Analysis of polyphenols, phytosterols, and bitter principles in Teucrium L. species. Cent Eur J Biol 7: 542-550 http://dx.doi.org/10.2478/s11535-012-0040-5

6. MALEŠ Ž, BABAC M, HAZLER PILEPIĆ K, ZOVKO M 2008 Quantitative analysis of the polyphenols in some species of the genus Teucrium L. Farm Glas 64: 169-177

7. MALEŠ Ž, HAZLER PILEPIĆ K, JAKUPOVIĆ L, ZADRAVEC D, MARIĆ S 2014 Determination of the content of flavonoids and phenolic acids in five species of the genus Teucrium L. Farm Glas 70: 231-241

8. MORTEZA-SEMNANI K, SAEEDI M, AKBARZADEH M 2011 Chemical Composition and Antimicrobial Activity of Essential Oil of Teucrium hyrcanicum L. J Essent Oil Bear Pl 14: 770775

9. GHARAIBEH M N, ELAYAN H H, SALHAB A S 1988 Hypoglycemic effects of Teucrium polium. J Ethnopharmacol 24: 93-99 http://dx.doi.org/10.1016/0378-8741(88)90139-0

10. SULEIMAN M M, DZENDA T, SANI C A 2008 Antidiarrhoeal activity of the methanol stem-bark extract of Annona senegalensis Pers. (Annonaceae). J Ethnopharmacol 116: 125-130

11. MALEŠ Ž, HAZLER PILEPIĆ K, PETROVIĆ L, BAGARIĆ I 2010 Quantitative analysis of phenolic compounds of Inula candida (L.) Cass. Period Biol 112: 307-310

12. HAZLER PILEPIĆ K, MALEŠ Ž 2013 Quantitative analysis of polyphenols in eighteen Hypericum taxa. Period Biol 115: 459-462

13. Meteorological and hydrological institute of Croatia $2014 \mathrm{http}: / /$ meteo.hr

14. DUARTE A R, SANTOS S C, SERAPHIN J C, FERRI P H 2010 Environmental influence on phenols and essential oils of Myrciaria cauliflora leaves. J Braz Chem Soc 21: 1672-1680 http://dx.doi. org/10.1590/S0103-50532010000900011 